\title{
Evaluating sources of uncertainty in modelling the impact of probabilistic climate change on sub-arctic palsa mires
}

\author{
S. Fronzek ${ }^{1}$, T. R. Carter ${ }^{1}$, and M. Luoto ${ }^{2}$ \\ ${ }^{1}$ Finnish Environment Institute (SYKE), Helsinki, Finland \\ ${ }^{2}$ Department of Geosciences and Geography, University of Helsinki, Finland
}

Received: 12 July 2011 - Revised: 22 September 2011 - Accepted: 25 September 2011 - Published: 8 November 2011

\begin{abstract}
We present an analysis of different sources of impact model uncertainty and combine this with probabilistic projections of climate change. Climatic envelope models describing the spatial distribution of palsa mires (mire complexes with permafrost peat hummocks) in northern Fennoscandia were calibrated for three baseline periods, eight state-of-the-art modelling techniques and 25 versions sampling the parameter uncertainty of each technique - a total of 600 models. The sensitivity of these models to changes in temperature and precipitation was analysed to construct impact response surfaces. These were used to assess the behaviour of models when extrapolated into changed climate conditions, so that new criteria, in addition to conventional model evaluation statistics, could be defined for determining model reliability. Impact response surfaces were also combined with climate change projections to estimate the risk of areas suitable for palsas disappearing during the 21st century. Structural differences in impact models appeared to be a major source of uncertainty, with $69 \%$ of the models giving implausible projections. Generalized additive modelling (GAM) was judged to be the most reliable technique for model extrapolation. Using GAM, it was estimated as very likely ( $>90 \%$ probability) that the area suitable for palsas is reduced to less than half the baseline area by the period 2030-2049 and as likely (>66\% probability) that the entire area becomes unsuitable by 2080-2099 (A1B emission scenario). The risk of total loss of palsa area was reduced for a mitigation scenario under which global warming was constrained to below $2{ }^{\circ} \mathrm{C}$ relative to pre-industrial climate, although it too implied a considerable reduction in area suitable for palsas.
\end{abstract}

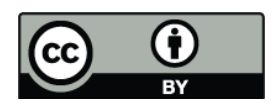

Correspondence to: S. Fronzek (stefan.fronzek@ymparisto.fi)

\section{Introduction}

Recent developments in climate modelling have made it possible to express projections of regional climate change for Europe probabilistically quantifying various aspects of climate modelling uncertainty (Räisänen and Ruokolainen, 2006; Murphy et al., 2007; Déqué and Somot, 2010; also see the review of Christensen et al., 2007, pages 921-925). These typically involve large ensembles of climate model simulations combined with some statistical analysis. Probability distributions are fitted for projected changes in key climate variables. The construction of such probabilistic projections of climate change was one of the main objectives of the EU-FP 6 ENSEMBLES project (van der Linden and Mitchell, 2009).

Multi-model ensemble climate projections pose both an opportunity and a challenge to impact modellers. They offer an opportunity to generate multiple estimates of future impacts, which can then be presented in terms of risk. However, through their sheer number they can also present a substantial computational challenge, especially for more complex impact models. Correspondingly, there have been few attempts to carry such projections through to impacts using impact models (e.g. Wilby and Harris, 2006; New et al., 2007). While such studies are themselves exploratory, they focus mainly on addressing uncertainties in future impacts attributable to projections of climate. Even less consideration has been paid to uncertainties of the impact estimates themselves, though the rare attempts that have been reported are still not as comprehensive as the analyses conducted for climate models (Rötter et al., 2011). For example, New et al. (2007) assessed the parameter uncertainty of a single hydrological model in combination with climate projection uncertainties from an ensemble of climate model outputs, but they did not undertake an intercomparison of different hydrological models to investigate structural uncertainties.

Published by Copernicus Publications on behalf of the European Geosciences Union. 
An alternative approach for assessing impact risks is to construct impact response surfaces from a sensitivity study of the impact model with respect to key climatic variables and to superimpose probabilistic climate change projections onto these (Jones, 2000a, b; Luo et al., 2007; Fronzek et al., 2010). The risk of exceeding critical impact thresholds can then be quantified by calculating the proportion of ensemble members lying above the threshold. In an earlier paper, we presented an example of this approach with a climatic envelope model, using a probabilistic projection of climate change constructed by re-sampling an ensemble of General Circulation Model (GCM) runs (Fronzek et al., 2010). However, impact model uncertainty was not quantified in that study.

Model uncertainty can be grouped into three different types: (1) uncertainty due to the structure of the model, (2) the parameter uncertainty of a single model, and (3) uncertainty of the initial conditions (Thuiller et al., 2009). Climatic envelope techniques have been applied widely to assess the impact of climate change on the spatial patterns of biodiversity and many aspects of their uncertainty have been discussed (Heikkinen et al., 2006; Jeschke and Strayer, 2008). It has also been suggested to quantify the uncertainty of envelope models by using large ensembles of impact models (Araújo and New, 2007; Thuiller et al., 2009). However, the application of envelope models with climate change scenarios often implies model extrapolations to climatic conditions that lie outside the range of values with which models have been calibrated. Moreover, testing the validity of extrapolations is difficult, as the response of future biodiversity range shifts cannot be measured (Araújo et al., 2005). For this reason, in this paper we advocate a rigorous testing of the sensitivity of envelope models to evaluate the robustness and plausibility of extrapolations.

We present an analysis that attempts to quantify impact model uncertainty, or at least some aspects of it, and combines this with probabilistic projections of climate change. We demonstrate this in a case study of sub-arctic palsa mires. Palsas are peat mounds with an ice core that is frozen all year round (Seppälä, 2011). They are located at the outer limit of the permafrost zone in sub-arctic regions, and hence are sensitive to even small changes in climate. Luoto et al. (2004a) and Fronzek et al. (2006) presented statistical climatic envelope models of the spatial distribution of palsa mires in northern Fennoscandia. One of these models was applied with probabilistic climate change projections derived from an ensemble of 21 General Circulation Models (GCMs), using the impact response surface approach to estimate the risk of palsa mire loss during the 21 st century (Fronzek et al., 2010). However, the uncertainty of the impact model was not assessed. This paper extends the previous analysis and has the following four objectives:
1. to quantify the uncertainties of climatic envelope models for palsa mires, where possible probabilistically;

2. to evaluate the robustness and plausibility of model extrapolations;

3. to apply the impact models with more comprehensive probabilistic projections of regional climate change generated in the ENSEMBLES project for the SRES A1B (moderate emissions) scenario, based on GCM simulations and observed constraints; and

4. to compare these probabilistic results with deterministic scenarios from an ensemble of atmosphere-ocean GCM simulations for the E1 stabilization scenario and the SRES A1B scenario, in order to gain insight on the effectiveness of mitigation policy in reducing the risk of disappearance of European palsa mires.

\section{Material and methods}

\subsection{Ensemble of palsa mire distribution models}

The presence or absence of palsa mires has been mapped using geomorphological and topographical maps and aerial photography (Luoto et al., 2004a; updated) onto a regular grid with $10^{\prime} \times 10^{\prime}$ spacing for Fennoscandia north of the Arctic Circle (Fig. 1). Gridded monthly mean temperature and annual precipitation observations for the period 1951-2000 were extracted from the Climatic Research Unit TS 1.2 dataset at the same $10^{\prime} \times 10^{\prime}$ resolution (New et al., 2002; Mitchell et al., 2004). Period averages were calculated for three $30 \mathrm{yr}$ baseline periods, 1951-1980, 19611990 and 1971-2000, offering a range of long-term reference climates. The 1951-1980 period was coolest and had the smallest annual precipitation, while 1971-2000 was the warmest and wettest of the three periods (Fig. 2). The following climate parameters were then derived for the three $30 \mathrm{yr}$ mean periods: Thawing degree days (TDD), freezing degree days (FDD), continentality (CONT) and annual precipitation (APREC). TDD and FDD, defined as the accumulated sum of daily mean temperatures above (TDD) or below (FDD) $0^{\circ} \mathrm{C}$, have been calculated from monthly mean temperatures using a method suggested by Kauppi and Posch (1985). This required information on the standard deviation of daily mean temperature around the monthly mean, for which a gridded dataset interpolated from station data was used (Fronzek and Carter, 2007). CONT was defined as the difference between the maximum and minimum of the mean monthly temperatures.

Eight climatic envelope modelling techniques implemented in the BIOMOD R-library (Version 1.0-2; Thuiller et al., 2009) were used to relate palsa presence/absence with the explanatory climatic variables: generalized linear modelling (GLM), generalized additive modelling (GAM), multivariate adaptive regression splines (MARS), classification 


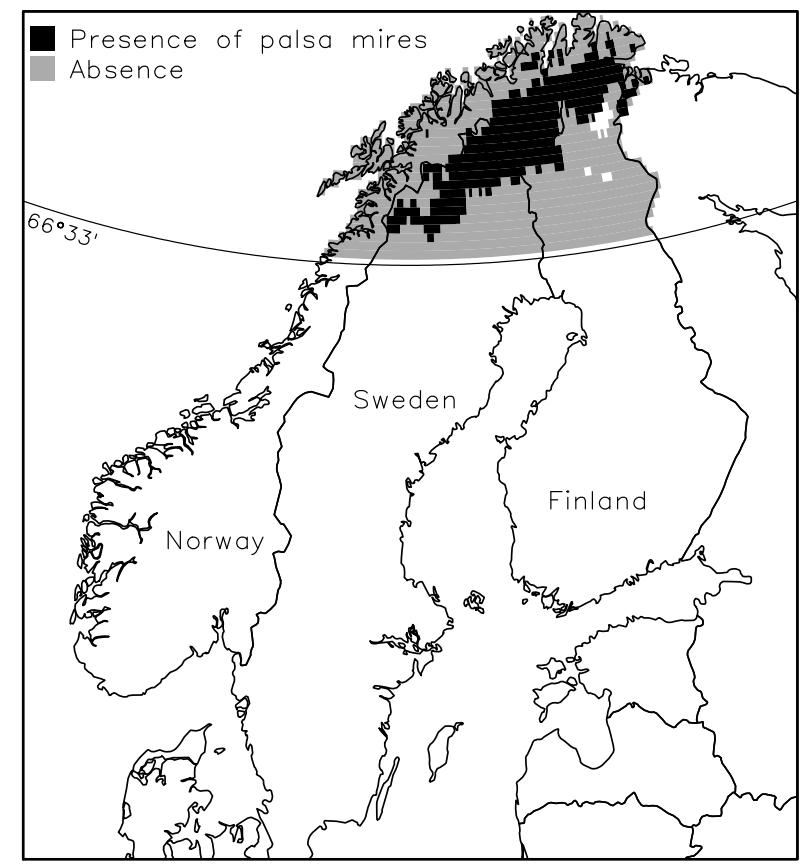

Fig. 1. Map of the study area showing the location of palsas in Northern Fennoscandia (Luoto et al. 2004, updated).

tree analysis (CTA), mixture discriminant analysis (MDA), artificial neural network (ANN), random forest (RF), and generalized boosting methods (GBM) (Table 1). Marmion et al. (2008) classify these methods into regression methods (GLM, GAM, MARS), classification methods (CTA, MDA) and machine learning methods (ANN, RF, GBM). RF and GBM use a large number of regression trees and could therefore also be described as classification methods. The models give values on a continuous scale between 0 and 1 ; to convert these into predicted presences or absences, a threshold was determined by minimizing the difference between correct presence and correct absence predictions.

For each of the 8 modelling techniques and each of the 3 baseline periods, we calibrated models by randomly splitting the data into calibration and evaluation sets 25 times resulting in $8 \times 3 \times 25=600$ models. The calibration data sets contained data from $70 \%$ of the grid cells retaining the same ratio of palsa presences and absences as in the full data sets; the remaining $30 \%$ of the grid cells were used as evaluation data sets. Although arbitrary, this proportion is commonly applied for the split-sampling of data (Araújo et al., 2005). All subsequent analyses of uncertainty should thus be regarded as conditional on the 70:30 split, which was applied consistently for all models.
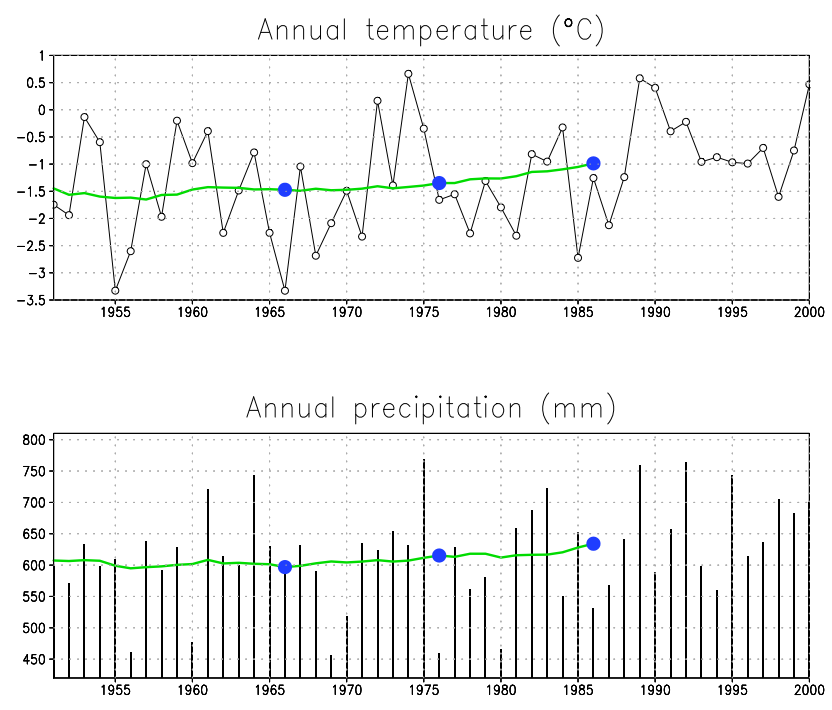

Fig. 2. Area-averages of annual mean temperature and precipitation (black lines), running $30 \mathrm{yr}$-averages centred at their mid-yr (green lines) and period-averages for 1951-1980, 1961-1990 and 19712000 (blue points) for the European land grid cell north of the Arctic Circle $\left(66.5^{\circ} \mathrm{N}\right)$ of the CRU_TS_2.02 dataset.

This ensemble of palsa mire distribution models samples three sources of impact model uncertainty: (1) initial conditions, by relating the observed palsa distribution with climatic conditions for different baseline periods, (2) model structure, by employing alternative statistical techniques to quantify palsa-climate relationships, and (3) model parameters, by sampling across the distribution of parameter values obtained for a single modelling technique (Table 2).

Two evaluation statistics were calculated for the evaluation and calibration data sets; the area under the receiver operating characteristics curve (AUC) and Cohen's kappa coefficient. AUC is defined as the area under the curve of the proportion of true positive to false positive predictions as a function of the threshold values (Heikkinen et al., 2006). A perfect model has an AUC value of 1 whereas a value of 0.5 indicates a discriminatory ability no better than chance. AUC values above 0.9 are usually regarded as indicating excellent model accuracy (Swets, 1988). The kappa coefficient is a measure of agreement between predictions and observations corrected for the probability of agreeing randomly (Heikkinen et al., 2006). A value of 1 indicates a perfect agreement; values close to 0 indicate poor agreement. Landis and Koch (1977) proposed the following classification of model performances using the Kappa statistics: $0.81-1.00=$ almost perfect; $0.61-0.8=$ substantial; $0.41-0.6=$ moderate; $0.21-$ $0.4=$ fair; $0.0-0.2=$ fail. The ratio of AUC values for the evaluation and calibration datasets was calculated as an indicator of model stability (Heikkinen et al., 2007). The same stability ratio was also calculated for the Kappa coefficient. These ratios were used to compare different palsa model versions with each other. 
Table 1. Description of climatic envelope modelling techniques (based on Fronzek et al., 2006; Heikkinen et al., 2006; Elith et al., 2008; Marmion et al., 2008).

\begin{tabular}{|c|c|}
\hline Technique & Description \\
\hline Generalized linear modelling (GLM) & $\begin{array}{l}\text { GLM is a parametric regression method that transforms a linear } \\
\text { combination of explanatory variables through a link function. } \\
\text { We used a logistic link function with polynomial terms and a } \\
\text { stepwise procedure to select the most significant variables based } \\
\text { on Akaike's information criterion. }\end{array}$ \\
\hline Generalized additive modelling (GAM) & $\begin{array}{l}\text { GAM is a non-parametric extension of GLM that allows more flexible } \\
\text { smooth functions. We used a spline smooth function with a degree } \\
\text { of smoothing of } 3 \text {. }\end{array}$ \\
\hline Multivariate adaptive regression splines (MARS) & $\begin{array}{l}\text { MARS is a non-parametric regression technique that partitions the data } \\
\text { to produce local models with either linear or non-linear relationships } \\
\text { between response and predictors. }\end{array}$ \\
\hline Classification tree analysis (CTA) & $\begin{array}{l}\text { CTA divides the data into regions spanned by the explanatory variables that } \\
\text { group together similar values of the response variable. Repeatedly dividing } \\
\text { the data builds a tree that is defined by thresholds for explanatory variables. }\end{array}$ \\
\hline Mixture discriminant analysis (MDA) & $\begin{array}{l}\text { MDA is a non-parametric classification method in which data are classified } \\
\text { as a mixture of normally distributed subclasses. MDA is an extension of } \\
\text { linear discriminant analysis. }\end{array}$ \\
\hline Random forest (RF) & $\begin{array}{l}\mathrm{RF} \text { is an ensemble classifier that generates multiple trees forming a } \\
\text { "forest" by randomly varying training data and explanatory variables. }\end{array}$ \\
\hline Generalized boosting methods (GBM) & $\begin{array}{l}\text { GBM combine two techniques: regression trees and boosting (an adaptive, } \\
\text { multi-model combination method for improving predictive performance). } \\
\text { The additive regression model is fitted using a forward, stagewise } \\
\text { procedure with simple trees as individual terms. We allowed a maximum } \\
\text { number of } 2000 \text { trees. }\end{array}$ \\
\hline Artificial neural network (ANN) & $\begin{array}{l}\text { ANNs are non-linear models that combine information from explanatory } \\
\text { variables using artificial nodes or "neurons" linked together through } \\
\text { weighted connections over multiple layers. }\end{array}$ \\
\hline
\end{tabular}

Since the model application is an extrapolation to climatic conditions outside the observations (see next section), two criteria were defined to distinguish models giving implausible results following extrapolation. A palsa model was regarded as implausible if, for no changes in precipitation:

1. increases (decreases) in suitability are projected for increased (decreased) temperature (tested at $-1^{\circ} \mathrm{C}, 0^{\circ} \mathrm{C}$, $1{ }^{\circ} \mathrm{C}, 3^{\circ} \mathrm{C}$ and $5^{\circ} \mathrm{C}$ ); and

2. the area projected as suitable does not totally disappear for a warming of $6^{\circ} \mathrm{C}$ relative to $1961-1990$.

While essentially arbitrary, the first criterion can be justified by the thawing effect of warming - higher air temperatures will warm the soil and hence increase the risk of thawing permafrost. A warming of $6^{\circ} \mathrm{C}$, as used in the second criterion, would imply mean annual temperatures above $0{ }^{\circ} \mathrm{C}$ for the whole study area, which is generally believed to be well above the upper limit for palsas in Fennoscandia (Seppälä, 2011). These are similar conditions as those found in central parts of Finland and Sweden for the period 1961-1990, and therefore far outside the current distribution of permafrost.

\subsection{Impact response surfaces}

Simulations with the 600 palsa models were conducted for each combination of temperature changes at $0.2^{\circ} \mathrm{C}$ increments between $-3{ }^{\circ} \mathrm{C}$ and $6.8^{\circ} \mathrm{C}$ and precipitation changes at $5 \%$ increments between $-30 \%$ and $50 \%$ relative to the 1961-1990 baseline period, which was also the baseline period of one of the climate change datasets (see below). Since the explanatory variables of the palsa models require monthly mean temperature, we applied a seasonal pattern taken from the average of an ensemble of AOGCM simulations to scale the annual temperature change to monthly changes (Fronzek et al., 2010). A seasonal pattern of precipitation changes was not needed as only annual precipitation was used as the explanatory variable in the palsa models.

For each combination of temperature and precipitation changes, we calculated the change in area suitable for palsa mires relative to the modelled suitable area for climatic conditions in the 1961-1990 baseline period. The results were then plotted as impact response surfaces that display the change in palsa area in relation to changes in precipitation and temperature. The response in change of suitability area 
Table 2. Sources of uncertainty in projecting climate change effects on palsa mires.

\begin{tabular}{llr}
\hline Source of uncertainty & Sampling method & Sample size \\
\hline Palsa impact model & & $3 \times 8 \times 25=600$ \\
\hline $\begin{array}{l}\text { Initial conditions } \\
\text { Model structure } \\
\text { Model parameters }\end{array}$ & $\begin{array}{l}\text { Sampling of the 30 yr baseline periods: 1951-1980, 1961-1990 and 1971-2000 } \\
\text { Ensemble of climatic envelope techniques }\end{array}$ & 3 \\
\hline Climate projection & Sampling of random sub-sets of the data for calibration & 8 \\
\hline GCM structure & Probabilistic projections of climate change & 25 \\
GCM parameters & of climate change from a statistical emulator & $10000+12$ \\
Observed constraints & based on GCM ensembles and observations & 12 \\
& for the SRES A1B emission scenario & 10000 \\
\hline $\begin{array}{l}\text { GCM structure/initial } \\
\text { conditions }\end{array}$ & $\begin{array}{l}\text { Individual GCM simulations (E1 } \\
\text { stabilization and SRES A1B) }\end{array}$ & 12 \\
\hline
\end{tabular}

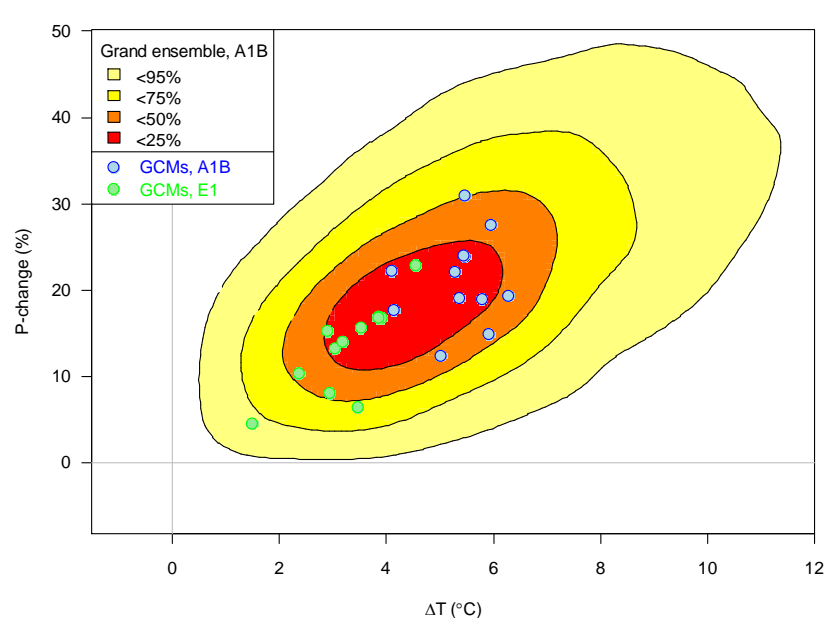

Fig. 3. Changes from 1961-1990 to 2080-2099 in annual mean temperature $\left({ }^{\circ} \mathrm{C}\right)$ and precipitation $(\%)$ over northern Lapland for the Grand Ensemble probabilistic projection (Harris et al., 2010) and an ensemble of GCM simulations for the E1 mitigation and SRES A1B scenarios (Johns et al., 2011). Probabilities are depicted as the percentage of projections enclosed within coloured zones.

was assumed to be constant outside the range of values for which the sensitivity of the palsa models has been calculated.

\subsection{Probabilistic climate projections and the risk of palsa disappearance}

The impact response surfaces were overlaid with projections of 21 st century climate change to estimate future impacts on palsa suitability. Two datasets describing changes in annual mean temperature and annual precipitation for northern Fennoscandia relative to the period 1961-1990 were obtained from the ENSEMBLES project (Fig. 3):

1. The "Grand Ensemble", which describes joint probabilities of annual mean temperature and precipitation changes for nine $20 \mathrm{yr}$ periods during the 21 st century (2000-2019, 2010-2029; 2080-2099) for the SRES A1B forcing scenario (Harris et al., 2010). This dataset combines information from perturbed physics ensembles, multi-model ensembles and observational constraints, and quantifies uncertainties in the leading physical, chemical and biological feedbacks. The data are available as joint frequency distributions with a sample size of 10000 .

2. Changes in temperature and precipitation extracted from 12 simulations of the E1 mitigation and the A1B non-mitigation scenarios with seven Earth System Models and GCMs (Johns et al., 2011). Both emission scenarios were quantified with the IMAGE 2.4 integrated assessment model (van Vuuren et al., 2007). E1 is an aggressive mitigation scenario aimed at stabilizing global warming below $2{ }^{\circ} \mathrm{C}$ relative to pre-industrial levels (Lowe et al., 2009). The A1B simulations with the same climate models allow an evaluation of the impact avoided by the E1 scenario. The quantification of A1B used here slightly differs from the SRES A1B marker scenario which was quantified with a different integrated assessment model (Nakićenović et al., 2000). Simulated changes were obtained for the periods 2030 2049 and 2080-2099.

The change in area suitable for palsas was evaluated from the impact response surface for the combination of temperature and precipitation change defined by each climate projection. For the Grand Ensemble we therefore obtained a distribution of 10000 impact estimates for each palsa model and time period. The probabilities of exceeding two impact thresholds were calculated from these distributions of impact estimates: loss of the entire palsa area and loss of more than half of the palsa area relative to the modelled baseline area. 
Table 3. Mean and standard deviation of the AUC evaluation statistics of the 25-member ensemble of palsa models for three calibration time periods.

\begin{tabular}{lrrr}
\hline Model type & $1951-1980$ & $1961-1990$ & $1971-2000$ \\
\hline GLM & $0.955 \pm 0.008$ & $0.956 \pm 0.008$ & $0.951 \pm 0.009$ \\
GAM & $0.952 \pm 0.009$ & $0.952 \pm 0.009$ & $0.947 \pm 0.010$ \\
MARS & $0.948 \pm 0.010$ & $0.951 \pm 0.009$ & $0.947 \pm 0.010$ \\
CTA & $0.920 \pm 0.013$ & $0.924 \pm 0.015$ & $0.908 \pm 0.022$ \\
MDA & $0.930 \pm 0.011$ & $0.934 \pm 0.012$ & $0.929 \pm 0.013$ \\
RF & $0.963 \pm 0.006$ & $0.966 \pm 0.006$ & $0.963 \pm 0.007$ \\
GBM & $0.949 \pm 0.009$ & $0.952 \pm 0.009$ & $0.946 \pm 0.010$ \\
ANN & $0.877 \pm 0.060$ & $0.857 \pm 0.117$ & $0.895 \pm 0.032$ \\
\hline
\end{tabular}

\section{Results}

\subsection{Model performance under baseline conditions}

Descriptive statistics for the 600 climatic envelope models are presented in Table 3. Nearly all models had AUC values greater than 0.9 for the evaluation data sets, indicating excellent model agreement, the exceptions being versions of the ANN and CTA models. 36 of the 75 ANN models had AUC values below 0.9 , with two models showing values below or equal to 0.5 , indicating model performance no better than chance. These two models also had Kappa coefficients of 0, indicating model failure. Eight of the 75 CTA models had AUC values below 0.9. ANN models had the largest variability in model performance.

RF models consistently had the highest AUC values ahead of GLM and GAM. The ratio of AUC values between evaluation and calibration data sets was highest for GLM and GAM (average of 0.997 over all 75 ensemble members) and lowest for CTA (0.955) and RF (0.964). Similar results were achieved for the ratio of Kappa coefficients between evaluation and calibration datasets, which ranged between 0.978 for the ensemble averages of GLM and GAM to 0.774 for CTA.

GAM was the only technique for which all models fulfilled the two plausibility criteria for extrapolating to climatic conditions outside the range of calibration data; GLM fulfilled these criteria in all but one of the 75 models (Table 4). Decreases in area suitable for palsas with warming were projected for nearly all CTA, RF and GBM models and the majority of ANN models, whereas all MDA and nearly all MARS models failed this criterion. The total disappearance of area suitable for palsas for a warming of $6^{\circ} \mathrm{C}$ was projected by only a few MARS, CTA, MDA and RF models and by none of the GBM models. Altogether, 185 of the 600 models fulfilled both plausibility criteria.

\subsection{Model behaviour under climate change}

Impact response surfaces were constructed to examine the behaviour of each model under climate change. The full set (25 versions of all eight model techniques for three calibration periods) is presented in Appendix A. Here we use selected examples to illustrate notable characteristics of model response.

Impact response surfaces for GAM and ANN models fulfilling the plausibility criteria are shown in Fig. 4a, b. The ensemble average of GAM calibrated for the 1961-1990 baseline period projects the total disappearance of area suitable for palsas with a warming of $4.5^{\circ} \mathrm{C}$, and the loss of half of the area under a warming of $1.5^{\circ} \mathrm{C}$ assuming no change in precipitation (Fig. 4a). Increases in precipitation enhance the decline of suitability; hence the warming required for total or $50 \%$ disappearance is smaller than that estimated without precipitation changes. The parameter uncertainty of GAM models gave a relatively narrow range of ca. $0.5^{\circ} \mathrm{C}$ for the curves describing the palsa loss with ranges becoming wider for precipitation changes larger than $\pm 10 \%$.

ANN models gave a much wider range of projections than GAM, even excluding those models not fulfilling the plausibility criteria (Fig. 4b). The 11-member ensemble average of ANN models projected the loss of half the palsa area for $1{ }^{\circ} \mathrm{C}$ warming and the total loss of palsa area for $4.9^{\circ} \mathrm{C}$ warming. Some other models resulted in more complex impact response surfaces, sometimes with non-monotonic relationships of palsa change with warming. One such example was a CTA ensemble member for which a warming of up to $2^{\circ} \mathrm{C}$ resulted in decreases in area suitable for palsas, but additional warming produced a reversal in response towards increased suitability (Fig. 4c). GLM produced impact response surfaces with small variations similar to GAM, while GBM, RF and CTA also resulted in relatively small ranges (not shown), although most of these models did not fulfil the criterion of projecting total palsa loss for a large amount of warming (cf. Table 4). The response surfaces of the MARS and MDA models showed a very large variation, and most of these in any case failed the plausibility criteria.

GAM impact response surfaces for models calibrated with 1951-1980 (1971-2000) climate were shifted towards projecting palsa area loss with less (more) warming and precipitation increases relative to the period 1961-1990, and largely retained the shape of the 1961-1990 impact response surfaces (Fig. 4a). This largely reflects the observed trends in temperature and precipitation between the three calibration periods (cf. Fig. 2).

\subsection{Estimating the risk of future loss of palsa suitability}

The joint distribution of temperature and precipitation changes projected in the Grand Ensemble remained outside the area of total palsa loss for the GAM ensemble average during the first future period, 2000-2019, but gradually 
Table 4. Percentage of palsa models simulating decreases in palsa suitability with increased temperature and the total disappearance with $6{ }^{\circ} \mathrm{C}$ warming relative to $1961-1990$ for three calibration time periods.

\begin{tabular}{l|ccc|ccc|c}
\hline \multirow{2}{*}{ Model type } & \multicolumn{6}{|c|}{ Decreased palsa suitability with warming } & \multicolumn{3}{|c|}{ Complete loss of palsa suitability } & with $6^{\circ} \mathrm{C}$ warming & Both criteria satisfied \\
\cline { 2 - 8 } & $1951-1980$ & $1961-1990$ & $1971-2000$ & $1951-1980$ & $1961-1990$ & $1971-2000$ & All periods \\
\hline GLM & 100 & 100 & 96 & 100 & 100 & 100 & 99 \\
GAM & 100 & 100 & 100 & 100 & 100 & 100 & 100 \\
MARS & 4 & 0 & 8 & 4 & 0 & 0 & 1 \\
CTA & 96 & 88 & 72 & 4 & 0 & 4 & 3 \\
MDA & 0 & 0 & 0 & 8 & 4 & 0 & 0 \\
RF & 88 & 44 & 44 & 12 & 0 & 4 & 5 \\
GBM & 100 & 96 & 100 & 0 & 0 & 0 & 0 \\
ANN & 56 & 64 & 72 & 44 & 48 & 36 & 39 \\
\hline
\end{tabular}

migrated across the threshold of total palsa loss for periods further in the future (Fig. 5). By the end of the 21st century, only a small fraction of the distribution remained below the impact threshold for $50 \%$ loss of suitable area (Fig. 5, bottom row right).

The distribution of changes for the E1 mitigation scenario ensemble differed little from that of the non-mitigation A1B ensemble for the period 2030-2049, with most simulations resulting in $75 \%$ to $100 \%$ of the palsa area becoming unsuitable (Fig. 5, centre row left). In contrast, by 2080-2099, the A1B points have all crossed the impact threshold of total palsa loss, whereas more than half of the E1 ensemble members projected that some areas would remain suitable for palsas (Fig. 5, bottom row right). Three E1 simulations even showed slightly cooler conditions at the end of the 21 st century compared to the 2030-2049 period, implying reversion of some previously unsuitable palsa areas.

\subsection{Uncertainties in risk estimates}

The estimated risk that all of the baseline palsa area becomes unsuitable by the end of the 21 st century varies widely when a full ensemble of models, including those not fulfilling the plausibility criteria, is applied (white boxes and whiskers in Fig. 6). For one model class, MARS, all models calibrated with 1961-1990 climate predicted a $0 \%$ probability for this impact threshold; this was also the case for all but 3 of the 25 MDA models. The remaining six model types showed median estimates of between 41 and $78 \%$. The total range was largest for ANN, one version of which also gave the highest risk of $84 \%$.

When only plausible models were considered, estimates of the risk of crossing the impact threshold for total area loss showed a much smaller range for ANN from 51 to $84 \%$ (11 models) while the ranges for GAM and GLM (all 25 models plausible) are unchanged (grey boxes and whiskers in Fig. 6). The medians of the three modelling techniques resulting in plausible models for the calibration period 19611990, ANN, GAM and GLM, spanned a similar range of uncertainty as that described by the parameter uncertainty across the GLM and ANN models, whereas the parameter uncertainty across the GAM models was much narrower.

The GAM model results were used to compare parameter uncertainties with initial condition uncertainties in estimates of risk (Appendix B describes how these sources of uncertainty were combined). The risk of total loss of suitable area for palsas increased throughout the 21st century from $0 \%$ ( $0 \%$ to $1 \%$; $90 \%$ confidence intervals) in 2000-2019 to $78 \%$ (68\% to $84 \%$ ) in 2080-2099 (Fig. 7). The risk of $50 \%$ loss increased from $72 \%$ (44\% to $92 \%$ ) in 2000-2019 to $100 \%$ (99\% to $100 \%$ ) by $2080-2099$, with all periods after 2020-2039 having median estimates above $95 \%$. The range of 25-model-averages for each of the three calibration periods was wider than the range of risk estimates spanned by parameter uncertainty for a single calibration period (black points vs. grey boxplots in Fig. 7). Initial conditions, therefore, had a greater contribution to the combined uncertainty of GAM models.

\section{Discussion}

\subsection{Comparison of climatic envelope modelling techniques}

The majority of the 600 palsa models using eight climatic envelope techniques showed excellent evaluation statistics based on the AUC accuracy diagnostics of Swets (1988), although a split-sampling method was used to divide the data into calibration and evaluation sets, which does not provide a truly independent evaluation as they are drawn from the same sample (Araújo et al., 2005). Exceptions were about half of the ANN and a tenth of the CTA models, which had less than excellent evaluation statistics. RF ranked highest in evaluation statistics, followed by GLM and GAM. These latter two models also performed best in two indicators of model stability defined as the ratios of evaluation statistics between evaluation and calibration data sets, while CTA ranked lowest. Some previous studies have reported comparable results when comparing the predictive performance 

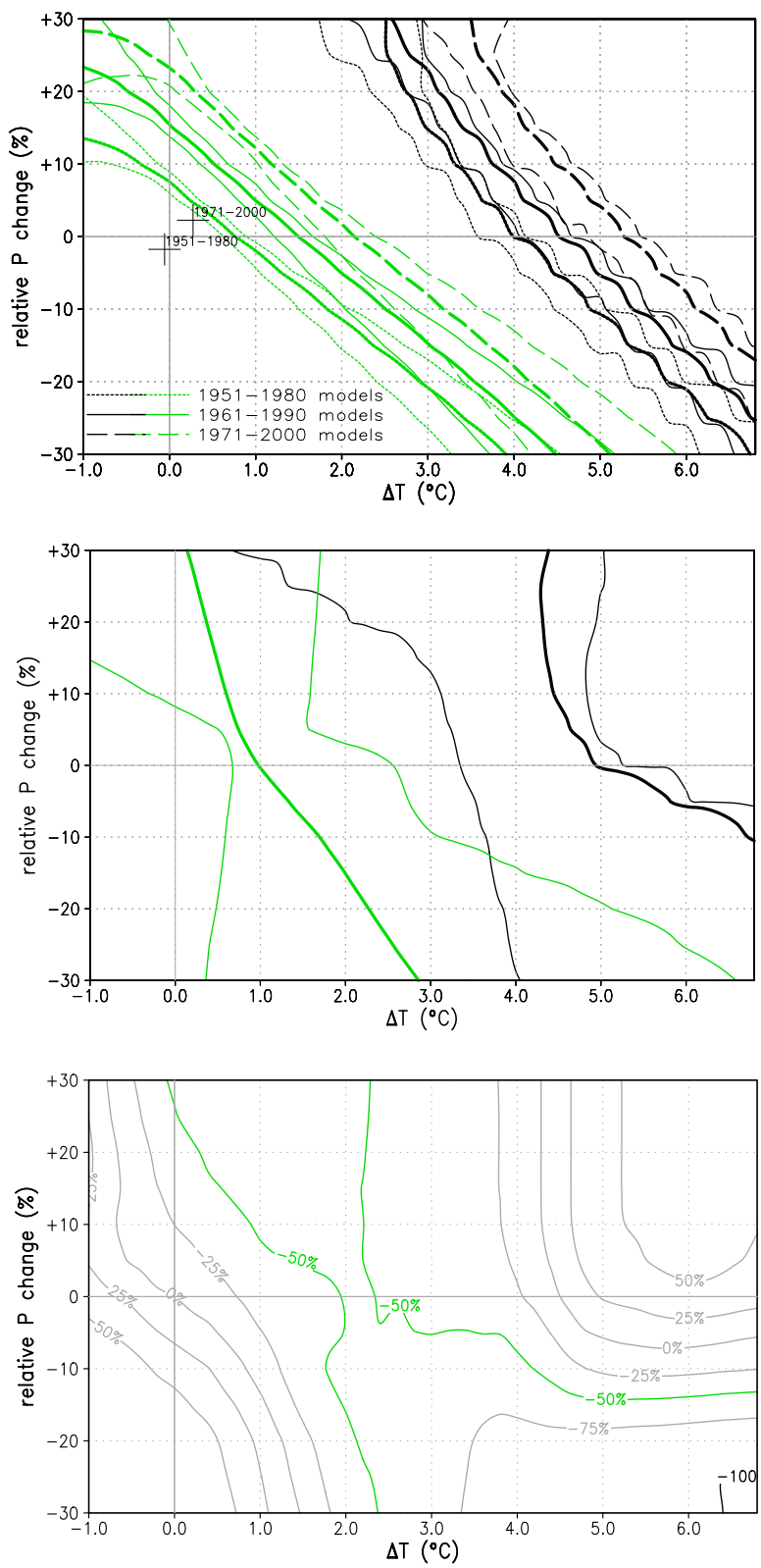

Fig. 4. Impact response surfaces showing the combinations of changes in annual mean temperature and precipitation for which half (green lines) and all (black lines) of the simulated palsa area becomes unsuitable relative to the simulated distribution for the 19611990 baseline period. The thicker lines show values for ensemble averages of: (a) GAM models calibrated for three different baseline periods ( 25 ensemble members each), with observed temperature changes relative to 1961-1990 also shown (crosses); (b) ANN models calibrated for the 1961-1990 baseline period (11 ensemble members); (c) a single CTA ensemble member. The thinner lines show the range for the ensembles. of envelope modelling techniques (Thuiller, 2003; Marmion et al., 2009; Luoto et al., 2010), although other studies resulted in a different ranking of techniques (e.g. Jeschke and Strayer, 2008) and general conclusions about a specific technique outperforming others are difficult to make. Jeschke and Strayer (2008) reviewed 12 studies reporting climatic envelope models of species ranges that also used a split-sampling method for evaluation; they reported an average value of $0.85 \pm 0.029$ (SE) for AUC. The AUC statistics reported here (Table 3) out-perform many of these other studies, indicating the high capability of palsa models to reproduce the observed spatial distribution. One possible explanation is that species distributions can be strongly affected by biotic and human factors, such as competition and land use, in addition to abiotic determinants such as climate. Another reason is that the distribution of northern Fennoscandian palsas is delimited solely by an upper limit (i.e. their southern range margin where climatic conditions become too warm). There is no lower limit, since the continuous permafrost that would define this does not exist in the study area.

Despite the generally good evaluation results, there was a large variation when these models were applied to modified climatic conditions, producing qualitatively different model outcomes. This demonstrates that the use of evaluation statistics calculated with split-sample data remains difficult and does not necessarily indicate if a model can also be used for extrapolation in climate change studies. Some models resulted in rather complex impact response surfaces that showed a non-monotonic relationship with warming like that shown for one of the CTA ensemble members in Fig. 4c. The introduction of plausibility criteria, based on knowledge of the processes governing palsa formation and maintenance (albeit subjectively interpreted), provides one means of discarding models that appear to behave unrealistically. Over fitting can be seen as one possible explanation why some models did not perform as well as others in the stability and plausibility criteria (cf. Araújo et al., 2005).

It is interesting to speculate on the potential for deploying plausibility criteria in other applications of climatic envelope models. For example, obvious thresholds in the relationship between distributions of plant, insect or bird species and climatic variables may not exist, or may depend on species traits that are poorly understood. The plausibility criteria defined in this study are therefore specific to the palsa distribution in northern Fennoscandia. Nevertheless, even if no clear thresholds are known, impact response surfaces could help to identify species distribution models that show an unrealistically complex response.

\subsection{Uncertainty and probabilistic impacts on palsa mires}

The ensemble of impact response surfaces has been overlaid with probabilistic projections of climate change to estimate the risk of more than half and of all the baseline area of 

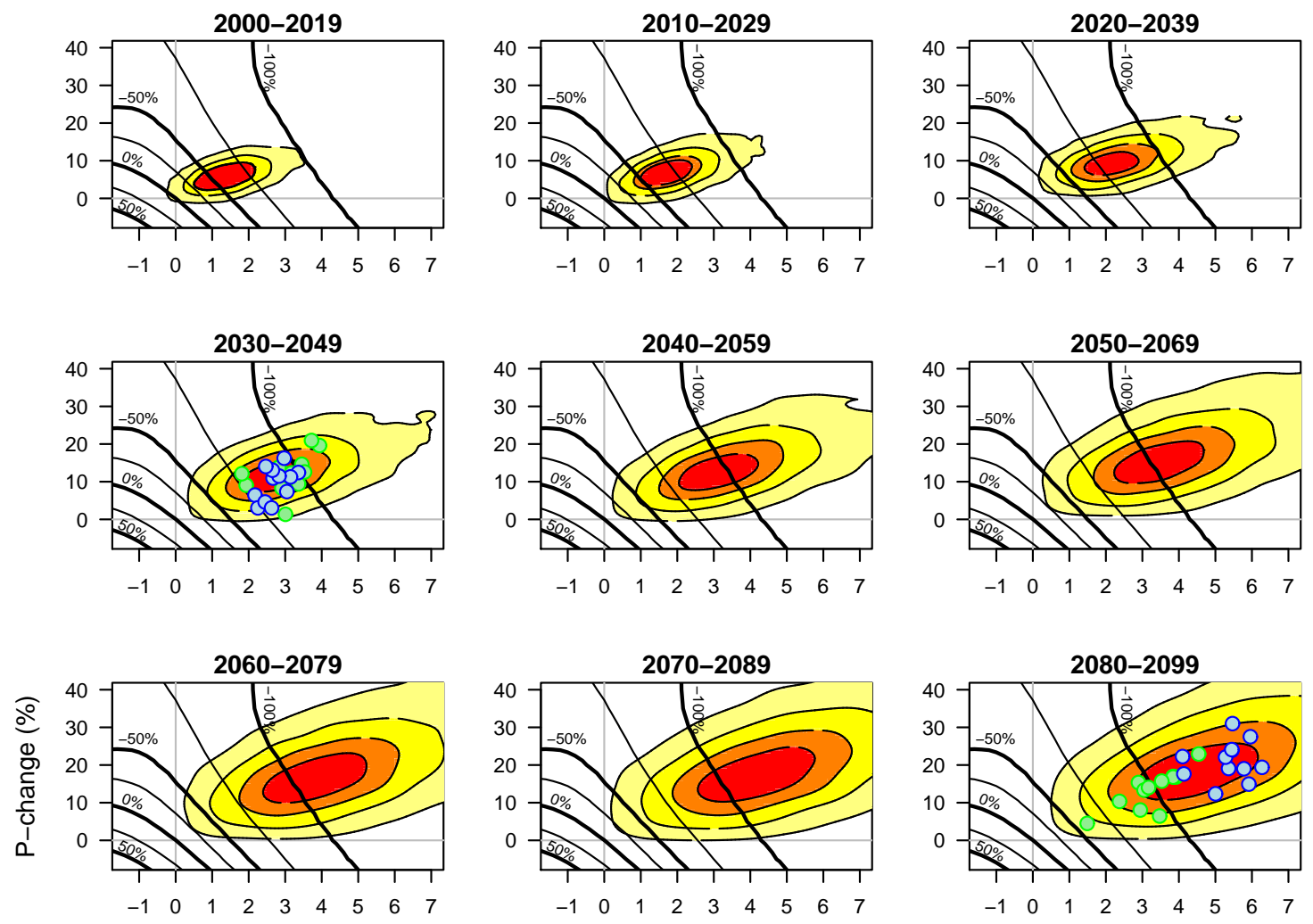

$\Delta \mathrm{T}\left({ }^{\circ} \mathrm{C}\right)$
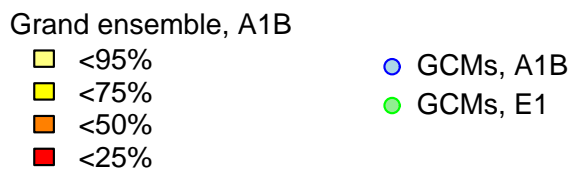

Fig. 5. Impact response surface showing the change in area suitable for palsa mires (contours in $25 \%$ steps from $50 \%$ to $-100 \%$ ) and projections of changes in mean annual temperature and precipitation relative to 1961-1990 for Grand Ensemble with A1B (coloured areas; Harris et al. 2010) and a GCM ensemble with forcing from the E1 mitigation scenario and A1B for nine periods in the 21st century. The impact response surface depicts the 25-model mean using GAM and 1961-1990 calibration period.

suitability becoming unsuitable for palsas. The Grand Ensemble probabilistic projection of climate change was used for this, which is one of the most rigorous attempts at quantifying regional climate change uncertainties over Europe reported, to date. This data set was developed for a single emission scenario, the moderate SRES A1B scenario, and therefore does not attempt to quantify the effect of higher or lower emissions. To address the lower end of emissions projections, we also presented an analysis of the impact of the E1 mitigation scenario on the climatic suitability of palsas.

Three potential sources of impact model uncertainty have been sampled, initial conditions expressed by comparing different baseline periods, model structure by using different modelling techniques, and model parameter uncertainty by randomly selecting different sub-sets of the data for calibration (cf. Table 2). The first two sources have fairly small sample sizes that are best suited to permit a comparison of periods or techniques, whereas the third source of uncertainty, which was sampled 25 times, lends itself more readily to a probabilistic interpretation if the sample members can be thought of as being representative of their probability distribution.

The observed data of the spatial distribution of palsas were constructed from several sources and it is difficult to determine exactly the period in time that these data represent. While the choice of the baseline period should ideally be matched with the time range of samples of the distribution, it can potentially have an effect on model performance (Roubicek et al., 2010). The three baseline periods investigated in this study represent a range of long-term climatic conditions that differ little in their spatial pattern. Evaluation statistics of models calibrated for different baseline periods therefore also showed little difference. However, the warmer and wetter baseline periods shifted the impact 


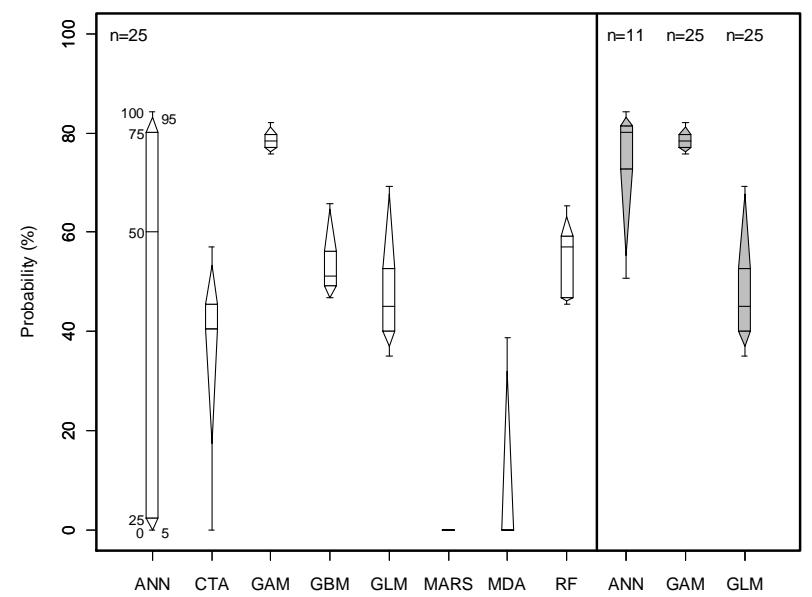

Fig. 6. Parameter uncertainty in estimating the probability that all palsa area becomes unsuitable by 2080-2099 for eight model types using all ensemble members calibrated for the period 1961-1990 ( $n=25$; white boxplots) and using only the "plausible" ensemble members (grey boxplots; see text for definition). Probabilities were estimated by evaluating impact response surfaces for the Grand Ensemble $(n=10000)$ with SRES A1B forcing. Boxplots show lower quartile, median and upper quartile; triangle peaks show the 5 th and 95th percentiles (defining $90 \%$ confidence intervals); whiskers delimit the smallest and largest values.

response surfaces (cf. Fig. 5a) and hence the choice of the baseline period had a marked effect on the resulting risk estimates (cf. Fig. 7).

The comparison of modelling techniques, discussed above, showed that not all techniques provided reliable longterm projections of palsa suitability for future climatic conditions. Thus, we used only a single technique, GAM, for assessing changes in suitable palsa area in more detail. The parameters of the GAM models were all calibrated for the same set of explanatory variables and using the same smoothing function, although in principle other settings in the calibration would have been possible (Thuiller, 2003). A larger set of explanatory variables to study the spatial distribution of palsas has been tested by Luoto et al. (2004a), whose most significant variables were used here.

A general assumption in climatic envelope modelling is that species/ecosystems distributions are at equilibrium with current climate. Recent studies have questioned how distant these current distributions are from equilibrium, and have further queried whether possible deviations from equilibrium would produce important biases in future projections (Heikkinen et al., 2006). Luoto and Seppälä (2003) showed that the present palsa distribution represents only a small remnant of its earlier, much wider distribution. Recent palsa degradation has generally occurred in the marginal parts of the palsa distribution area (Luoto et al., 2004b). These dynamics may cause a possible time lag of climate change and permafrost thaw which is not taken into account by static envelope models (Fronzek et al., 2006).

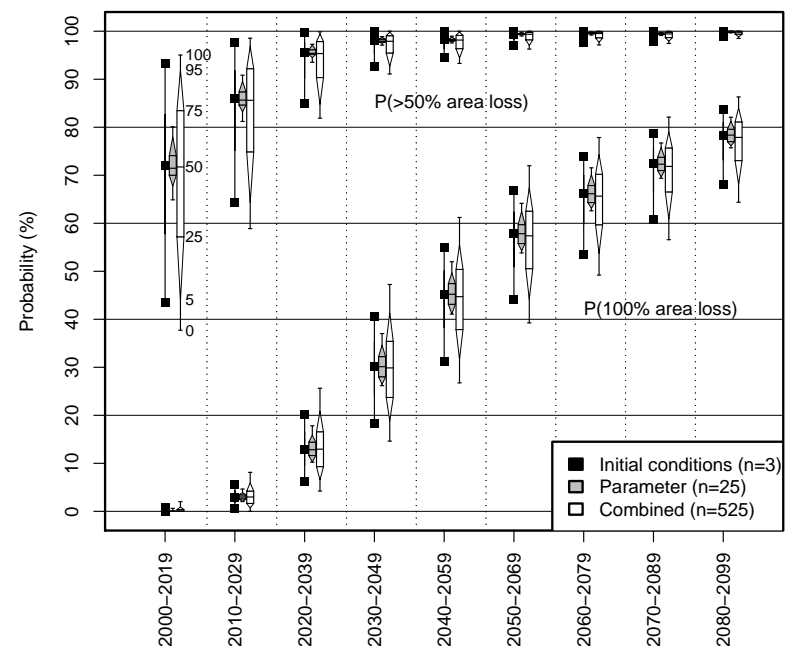

Fig. 7. Confidence intervals on estimated probabilities of half (upper boxplots) and all (lower boxplots) palsa areas becoming unsuitable for $20 \mathrm{yr}$ periods during the 21 st century relative to 1961-1990 for initial conditions (black points), parameter uncertainty (gray boxplots) and a combination of the two for the ensemble of GAM (white boxplots). Initial condition uncertainty was calculated as GAM ensemble averages of 25 models each calibrated for different baseline periods (1951-1980, 1961-1990, 1971-2000); parameter uncertainty is shown for models calibrated for the period 19611990; the combined confidence intervals were calculated by sampling between the baseline periods (see Appendix B). Probabilities were estimated by evaluating the impact response surface for the Grand Ensemble $(n=10000)$ with SRES A1B forcing. Boxplots show lower quartile, median and upper quartile; triangle peaks show the 5th and 95th percentiles (defining $90 \%$ confidence intervals); whiskers delimit the smallest and largest values.

Apart from uncertainties in the statistical modelling techniques, there are also other sources of impact model uncertainty that merit consideration. These include:

1. the effect of non-climatic factors, such as the distribution of a sufficiently thick peat layer that is needed to form a palsa (Seppälä, 1988) - this would affect possible expansions of palsa areas for cooling scenarios to be restricted to peat areas, but does not affect estimates of contraction directly. Indirectly, the lack of information on peat thickness might also decrease the explanatory power of models;

2. the impact response surface approach, which introduces additional error as it requires an assumption about the seasonal cycle of temperature changes - this mainly affects the tails of the distribution causing an underestimation of risk of up to ca. $5 \%$ (Fronzek et al., 2010; their Fig. 9).

The analysis showed a high risk of reduction in area suitable for palsa mires during the 21 st century. The estimated risk for overlapping $20 \mathrm{yr}$ periods during the 21 st century is similar 
to earlier estimates obtained with a re-sampled ensemble of GCMs for overlapping $30 \mathrm{yr}$ periods (Fronzek et al., 2010). Using a single GAM model, the earlier estimate of total palsa loss for the A1B scenario by the end of the 21 st century is at the high end of the impact range presented here, whereas estimates for the A2 (high emissions) and B1 (low emissions) scenarios were outside the range. The risk of total palsa loss by 2080-2099 was reduced, but not totally avoided, for the E1 mitigation scenario compared to the A1B non-mitigation scenario, indicating that mitigation policies could preserve some areas of suitability for palsas. However, even under the E1 scenario, the current distribution of palsa mires is projected to decrease markedly by the end of the 21 st century.

\section{Conclusions}

We presented an analysis of the risk of palsa disappearance from Northern Fennoscandia during the 21st century that used probabilistic projections of climate change and compared three different sources of impact model uncertainty: (1) initial condition, (2) structural and (3) parameter uncertainty. A large ensemble of 600 model versions describing the spatial distribution of a single habitat type (palsa mires) was calibrated and analysed - this ensemble is much larger than those used to date in studies of habitat or species distributions.

Impact model parameter uncertainty was quantified with ensembles of palsa models that allowed a probabilistic interpretation. The comparison of eight state-of-the-art climatic envelope modelling techniques demonstrated that the use of evaluation statistics based on observed distributions, such as AUC or kappa, does not necessarily indicate that a model can also be used for extrapolation in climate change studies. This study has introduced two criteria for judging the plausibility of model extrapolations based on the sensitivity of palsa models to changes in climate.

Structural differences in impact models appeared to be a major source of uncertainty. Some modelling techniques and altogether $69 \%$ of the model versions were judged to be unreliable and gave implausible results. GAM proved to be the most reliable technique for model extrapolation, based on the two criteria, and was therefore used to estimate impacts for the 21st century. Parameter uncertainty for GAM was smaller than the uncertainty due to different definitions of the baseline period.

We demonstrated how impact response surfaces can be used to depict the sensitivity of impacts to climate change and how these can help to evaluate model extrapolations because they show the model behaviour over a large range of climatic conditions. Combined with a definition of criteria for evaluating model plausibility, it is recommended that such procedures be followed prior to the application of climatic envelope models in climate change studies that involve extrapolation.
Impact response surfaces can also be used, in combination with probabilistic projections of climate change, to estimate risks of future impacts. The risk of reduced Northern Fennoscandian area suitable for palsas to less than half the baseline area was quantified as very likely ( $>90 \%$ probability; 90\% confidence) for periods from 2030-2049 onwards, with total loss of suitability judged as likely ( $>66 \%$ probability; $90 \%$ confidence) by 2080-2099 under the A1B emission scenario and using an ensemble of 75 GAM palsa models (confidence based on 5 to 95 percentiles of combined box plots in Fig. 7). The risk of total loss of palsa area from Northern Fennoscandia was reduced for a mitigation scenario under which global warming was constrained to below $2{ }^{\circ} \mathrm{C}$ relative to pre-industrial climate, although it, too, implied a considerable reduction in area suitable for palsas.

\section{Appendix A}

\section{Impact response surfaces of the full ensemble of palsa climatic envelope models}

Figures A1-A3 present impact response surfaces of all 600 palsa climatic envelope models.

\section{Appendix B}

\section{Combination of parameter and initial conditions uncertainties}

For practical reasons, the sampling of uncertainty due to initial conditions was limited to three baseline periods, 19511980, 1961-1990 and 1971-2000, although in principle one could have sampled other long-term periods. The periods 1951-1980 and 1971-2000 approximately (and coincidentally) demarcate the range of running $30 \mathrm{yr}$ averages for the second half of the 20th century, with intermediate climatic conditions represented by 1961-1990 (Fig. 2). As a consequence, combining the parameter uncertainties of palsa models calibrated for each of the three baseline periods would result in an overestimation of the spread of the distribution (i.e. two extremes and an intermediate distribution). To account for this, we assumed a linear progression between the palsa loss risks for 1951-1980 and 1971-2000. Next, we re-sampled the three estimated distributions of palsa loss risk by shifting them with modified means at equal increments between the means of the GAM models calibrated with each baseline climate (to simulate overlapping $30 \mathrm{yr}$ mean climates with an annual time step). This resulted in a combination of 21 individual distributions, comprising three sets of seven iterations of the 1951-1980, 1961-1990 and 1971-2000 distributions, respectively (Fig. A4, short orange boxplots). The combination of these 21 distributions (labelled "Adjusted mean" in Fig. A4) spans the same range as the three individual parameter uncertainty distributions 

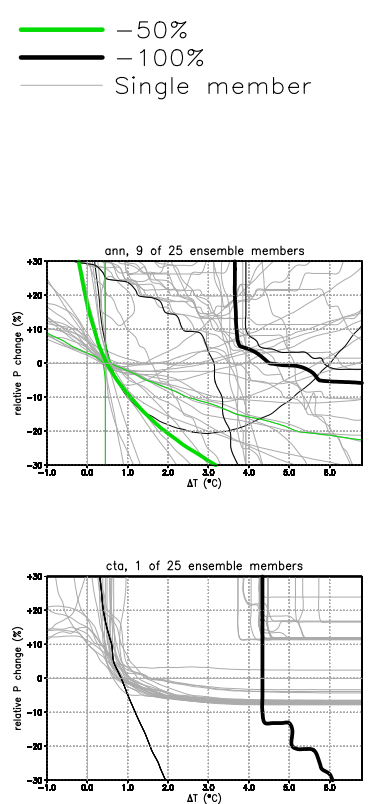
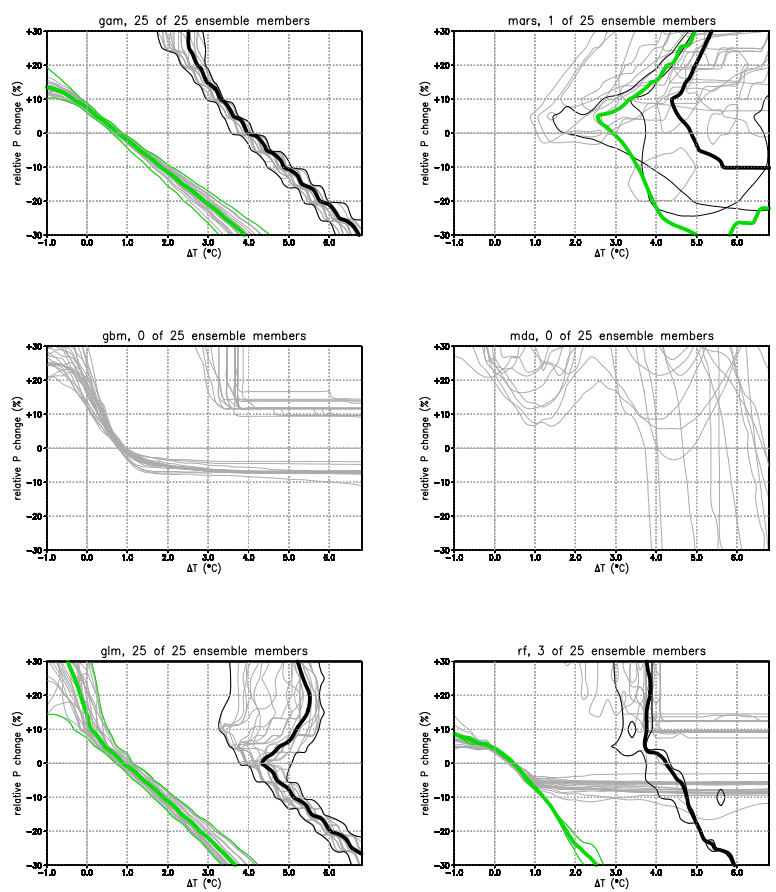

Fig. A1. Impact response surfaces showing the combinations of changes in annual mean temperature and precipitation for which half (green lines) and all (black lines) of the simulated palsa area becomes unsuitable relative to the simulated distribution for the 1961-1990 baseline period for eight climatic envelope modelling techniques. The thicker lines show values for ensemble averages of all plausible models (see text) calibrated for the 1951-1980 baseline period, the thinner lines show the range for the ensembles. Impact response surfaces of individual models, including those that failed the plausibility criteria, are shown with gray lines. The name of the technique and the number of plausible models is given as a title for each sub-graph.
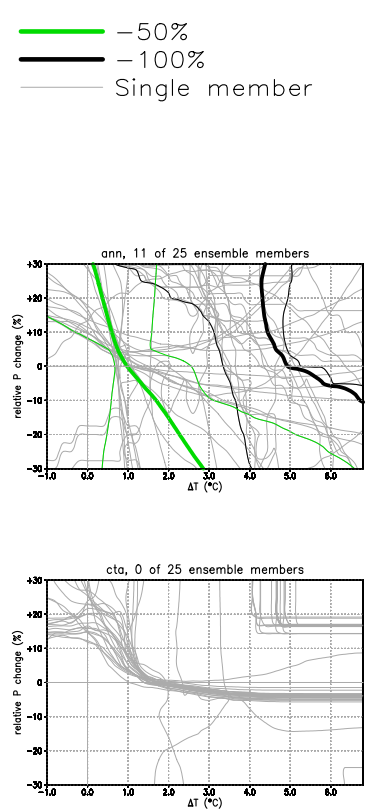
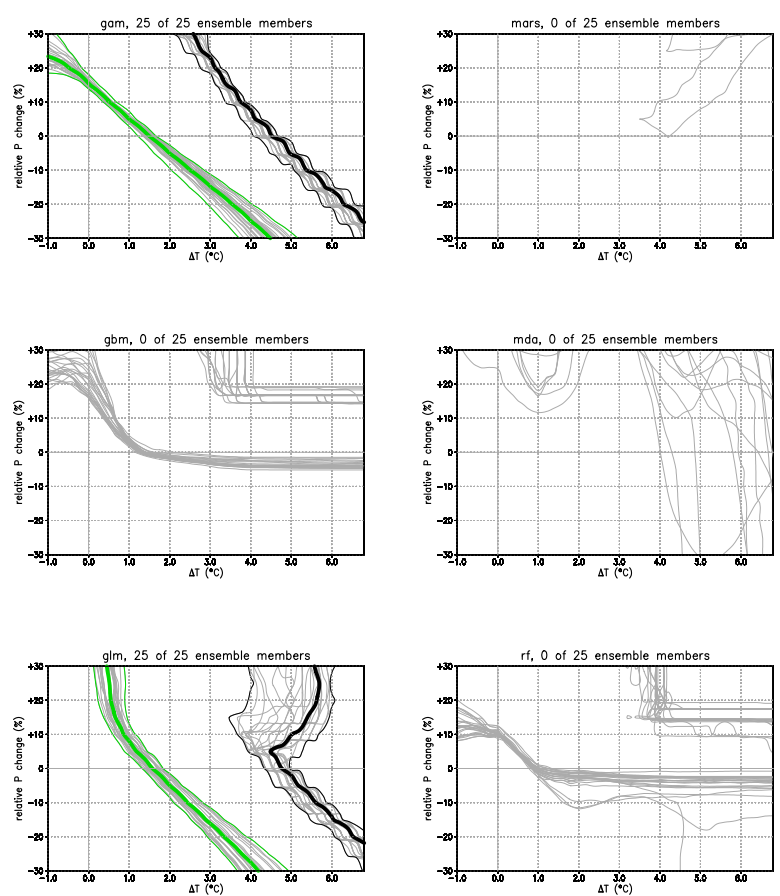

Fig. A2. As in Fig. A1, but for models calibrated for the 1961-1990 baseline period. 

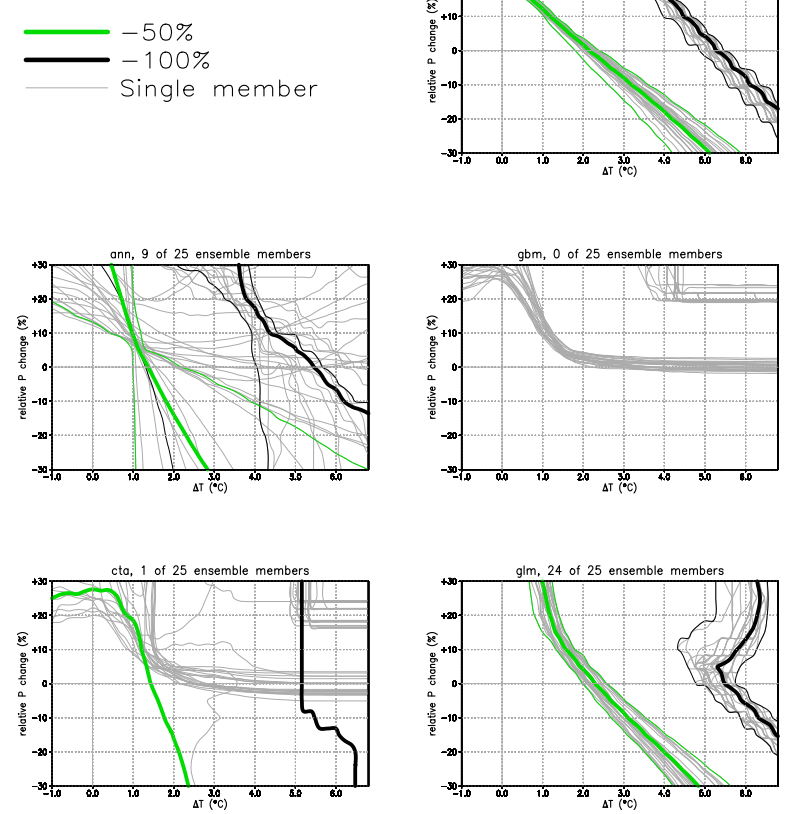
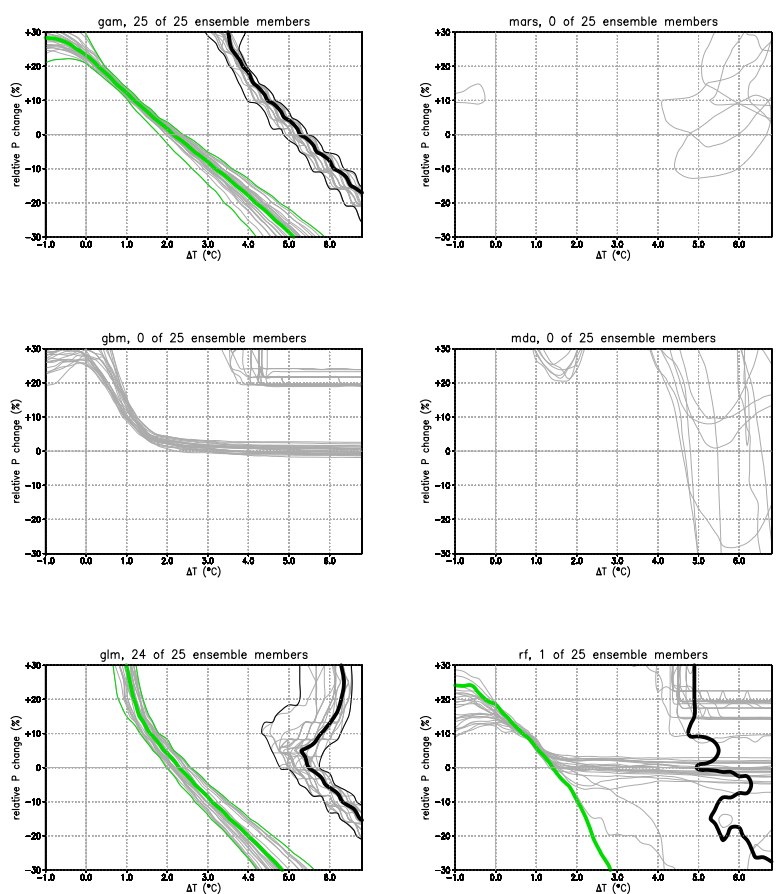

Fig. A3. As in Fig. A1, but for models calibrated for the 1971-2000 baseline period.

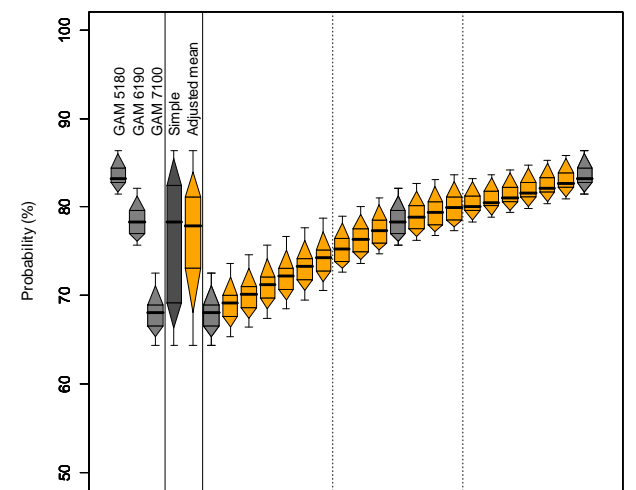

Fig. A4. Confidence intervals on probabilities of all palsa areas becoming unsuitable by 2080-2099 estimated with GAM ensembles calibrated for different baseline periods (1951-1980, 19611990, 1971-2000; gray boxplots), two approaches for estimating the combined parameter and initial conditions uncertainty by a simple sum of the individual distributions (darkgray boxplots) and by summing re-sampled distributions with adjusted mean (orange boxplots). Probabilities were estimated by evaluating the impact response surface for the Grand Ensemble $(n=10000)$ with SRES A1B forcing. Boxplots show lower quartile, median and upper quartile; triangle peaks show the 5th and 95th percentiles (defining $90 \%$ confidence intervals); whiskers delimit the smallest and largest values.

(GAM5180, GAM6190 and GAM7100 in Fig. A4), but has thinner tails then a simple combination of these three distributions (labelled "Simple" in Fig. A4).
Acknowledgements. We thank Glen Harris, Met Office Hadley Centre, for providing probabilistic climate change projections and Ines Höschel, Freie Universität Berlin, for regional averages of AOGCM simulations. We thank Risto K. Heikkinen for fruitful discussions and Pam Berry, Jørgen Olesen and one anonymous referee for providing constructive comments on an earlier version of this manuscript. This study was funded by the European Commission's Sixth Framework Programme through the ENSEMBLES project (contract GOCE-CT-2003-505539) and by the Academy of Finland (decisions 127239 and 140806).

Edited by: J. E. Olesen

Reviewed by: M. Semenov and P. Berry

\section{References}

Araújo, M. B. and New, M.: Ensemble forecasting of species distributions, Trends Ecol. Evol, 22, 42-47, 2007.

Araújo, M. B., Pearson, R. G., Thuiller, W., and Erhard, M.: Validation of species-climate impact models under climate change, Global Change Biol., 11, 1504-1513, 2005.

Christensen, J. H., Hewitson, B., Busuioc, A., Chen, A., Gao, X., Held, I., Jones, R., Kolli, R. K., Kwon, W.-T., Laprise, R., Rueda, V. M., Mearns, L., Menéndez, C. G., Räisänen, J., Rinke, A., Sarr, A., and Whetton, P.: Regional Climate Projections, in: Climate Change 2007: The Physical Science Basis. Contribution of Working Group I to the Fourth Assessment Report of the Intergovernmental Panel on Climate Change, edited by: Solomon, S., Qin, D., Manning, M., Chen, Z., Marquis, M., Averyt, K. B., Tignor, M., and Miller, H. L., Cambridge University Press, Cambridge, UK and New York, USA, 847-940, 2007. 
Déqué, M. and Somot, S.: Weighted frequency distributions express modelling uncertainties in the ENSEMBLES regional climate experiments, Clima. Res., 44, 195-209, doi:10.3354/cr00866, 2010.

Elith, J., Leathwick, J. R., and Hastie, T.: A working guide to boosted regression trees, J. Anim. Ecol., 77, 802-813, doi:10.1111/j.1365-2656.2008.01390.x, 2008.

Fronzek, S. and Carter, T. R.: Assessing uncertainties in climate change impacts on resource potential for Europe based on projections from RCMs and GCMs, Climatic Change, 81 (Suppl. 1), 357-371, 2007.

Fronzek, S., Luoto, M., and Carter, T. R.: Potential effect of climate change on the distribution of palsa mires in subarctic Fennoscandia, Clima. Res., 32, 1-12, 2006.

Fronzek, S., Carter, T. R., Räisänen, J., Ruokolainen, L., and Luoto, M.: Applying probabilistic projections of climate change with impact models: a case study for sub-arctic palsa mires in Fennoscandia, Climatic Change, 99, 515-534, doi:10.1007/s10584-009-9679-y, 2010.

Harris, G. R., Collins, M., Sexton, D. M. H., Murphy, J. M., and Booth, B. B. B.: Probabilistic projections for 21 st century European climate, Nat. Hazards Earth Syst. Sci., 10, 2009-2020, doi:10.5194/nhess-10-2009-2010, 2010.

Heikkinen, R. K., Luoto, M., Araújo, M. B., Virkkala, R., Thuiller, W., and Sykes, M. T.: Methods and uncertainties in bioclimatic envelope modelling under climate change, Prog. Phys. Geog., 30, 751-777, 2006.

Heikkinen, R. K., Luoto, M., Kuussaari, M., and Toivonen, T.: Modelling the spatial distribution of a threatened butterfly: Impacts of scale and statistical technique, Landscape and Urban Plann., 79, 347-357, 2007.

Jeschke, J. M. and Strayer, D. L.: Usefulness of Bioclimatic Models for Studying Climate Change and Invasive Species, Ann. NY. Acad. Sci., 1134, 1-24, doi:10.1196/annals.1439.002, 2008.

Johns, T., Royer, J. F., Höschel, I., Huebener, H., Roeckner, E., Manzini, E., May, W., Dufresne, J. L., Otterå, O., van Vuuren, D., Salas y Melia, D., Giorgetta, M., Denvil, S., Yang, S., Fogli, P., Körper, J., Tjiputra, J., Stehfest, E., and Hewitt, C.: Climate change under aggressive mitigation: the ENSEMBLES multi-model experiment, Clim. Dynam., doi:10.1007/s00382011-1005-5, 2011.

Jones, R. N.: Managing Uncertainty in Climate Change Projections - Issues for Impact Assessment, Climatic Change, 45, 403-419, 2000a.

Jones, R. N.: Analysing the risk of climate change using an irrigation demand model, Clima. Res., 14, 89-100, 2000 b.

Kauppi, P. and Posch, M.: Sensitivity of boreal forests to possible climatic warming, Climatic Change, 7, 45-54, 1985.

Landis, J. R. and Koch, G. G.: The Measurement of Observer Agreement for Categorical Data, Biometrics, 33, 159-174, 1977.

Lowe, J. A., Hewitt, C. D., van Vuuren, D. P., Johns, T. C., Stehfest, E., Royer, J.-F., and van der Linden, P. J.: New Study For Climate Modeling, Analyses and Scenarios, Eos, Trans. Am. Geophys. Union, 90, 181, doi:10.1029/2009EO210001, 2009.

Luo, Q., Bellotti, W., Williams, M., Cooper, I., and Bryan, B.: Risk analysis of possible impacts of climate change on South Australian wheat production, Climatic Change, 85, 89-101, 2007.

Luoto, M. and Seppälä, M.: Thermokarst ponds as indicators of the former distribution of palsas in Finnish Lapland, Permafrost
Periglac., 14, 19-27, doi:10.1002/ppp.441, 2003.

Luoto, M., Fronzek, S., and Zuidhoff, F. S.: Spatial modelling of palsa mires in relation to climate in Northern Europe, Earth Surf. Proc. Land., 29, 1373-1387, 2004a.

Luoto, M., Heikkinen, R. K., and Carter, T. R.: Loss of palsa mires in Europe and biological consequences, Environ. Conserv., 31, $1-8,2004 b$.

Luoto, M., Marmion, M., and Hjort, J.: Assessing spatial uncertainty in predictive geomorphological mapping: A multi-modelling approach, Comput. Geosci., 36, 355-361, doi:10.1016/j.cageo.2009.07.008, 2010.

Marmion, M., Hjort, J., Thuiller, W., and Luoto, M.: A comparison of predictive methods in modelling the distribution of periglacial landforms in Finnish Lapland, Earth Surf. Proc. Land., 33, 22412254, doi:10.1002/esp.1695, 2008.

Marmion, M., Luoto, M., Heikkinen, R. K., and Thuiller, W.: The performance of state-of-the-art modelling techniques depends on geographical distribution of species, Ecol. Model., 220, 35123520, 2009.

Mitchell, T. D., Carter, T. R., Jones, P. D., Hulme, M., and New, M.: A comprehensive set of high-resolution grids of monthly climate for Europe and the globe: the observed record (1901-2000) and 16 scenarios (2001-2100), Tyndall Centre Working Paper, 55, 29 pp., 2004.

Murphy, J. M., Booth, B. B. B., Collins, M., Harris, G. R., Sexton, D. M. H., and Webb, M. J.: A methodology for probabilistic predictions of regional climate change from perturbed physics ensembles, Philosophical Transactions of the Royal Society A, Mathematical Physical and Engineering Sciences, 365, 19932028, doi:10.1098/rsta.2007.2077, 2007.

Nakićenović, N., Alcamo, J., Davis, G., de Fries, B., Fenhann, J., Gaffin, S., Gregory, K., Grübler, A., Jung, T. Y., Kram, T., La Rovere, E. L., Michaelis, L., Mori, S., Morita, T., Pepper, W., Pitcher, H., Price, L., Raihi, K., Roehrl, A., Rogner, H.-H., Sankovski, A., Schlesinger, M., Shukla, P., Smith, S., Swart, R., von Rooijen, S., Victor, N., and Dadi, Z.: Emissions Scenarios, A Special Report of Working Group III of the Intergovernmental Panel on Climate Change, Cambridge University Press, Cambridge, 599, 2000.

New, M., Lister, D., Hulme, M., and Makin, I.: A high-resolution data set of surface climate over global land areas, Clima. Res., 21, 1-25, 2002.

New, M., Lopez, A., Dessai, S., and Wilby, R.: Challenges in using probabilistic climate change information for impact assessments: an example from the water sector, Philos. T. Roy. Soc. A, 365, 2117-2131, 2007.

Räisänen, J. and Ruokolainen, L.: Probabilistic forecasts of nearterm climate change based on a resampling ensemble technique, Tellus, 58, 461-472, 2006.

Rötter, R. P., Carter, T. R., Olesen, J. E., and Porter, J. R.: Cropclimate models need an overhaul, Nat. Clim. Change, 1, 175177, doi:10.1038/nclimatE1152, 2011.

Roubicek, A. J., VanDerWal, J., Beaumont, L. J., Pitman, A. J., Wilson, P., and Hughes, L.: Does the choice of climate baseline matter in ecological niche modelling?, Ecol. Model., 221, 22802286, 2010.

Seppälä, M.: Palsas and related forms, in: Advances in Periglacial Geomorphology, edited by: Clark, M. J. and John Wiley and Sons, Chichester, 247-278, 1988. 
Seppälä, M.: Synthesis of studies of palsa formation underlining the importance of local environmental and physical characteristics, Quaternary Res., 75, 366-370, 2011.

Swets, K.: Measuring the accuracy of diagnostic systems, Science, 240, 1285-1293, 1988.

Thuiller, W.: BIOMOD - optimizing predictions of species distributions and projecting potential future shifts under global change, Global Change Biol., 9, 1353-1362, doi:10.1046/j.13652486.2003.00666.x, 2003.

Thuiller, W., Lafourcade, B., Engler, R., and Araújo, M. B.: BIOMOD - a platform for ensemble forecasting of species distributions, Ecography, 32, 369-373, doi:10.1111/j.16000587.2008.05742.x, 2009. van der Linden, P. and Mitchell, J. F. B.: ENSEMBLES: Climate Change and its Impacts: Summary of research and results from the ENSEMBLES project, Met Office Hadley Centre, FitzRoy Road, Exeter EX1 3 PB, UK, 160, 2009.

van Vuuren, D., den Elzen, M., Lucas, P., Eickhout, B., Strengers, B., van Ruijven, B., Wonink, S., and van Houdt, R.: Stabilizing greenhouse gas concentrations at low levels: an assessment of reduction strategies and costs, Climatic Change, 81, 119-159, doi:10.1007/s10584-006-9172-9, 2007.

Wilby, R. L. and Harris, I.: A framework for assessing uncertainties in climate change impacts: Low-flow scenarios for the River Thames, UK, Water Resour. Res., 42, W02419, doi:10.1029/2005WR004065, 2006. 